\title{
Mapping Global Road Networks
}

\author{
Wenxiang Wu and Lingyun Hou
}

\section{Introduction}

Various studies have put forward different methods for reasonably determining the development scale of regional road networks according to the economic development and traffic conditions of each country, and formed some conventional methods for projecting the future scale of road networks, such as land coefficient method, elastic coefficient method, time series method, connectivity analysis method, and generalized cost method. Most of the methods are based on the analysis of the existing data to derive the development pattern so as to determine the road network scale in a future year. The factors related to road network scale are land use type, economic development, and population growth. The object of this study is the global road system. In view of the large spatial scale of the research object, we selected the land coefficient method that is suitable for large-scale projection for future global road network scale.

In order to evaluate the response of the global road system to climate change and accurately explain the current global road spatial distribution characteristics, we spatially processed the current global road length data (2010) and produced the global road length raster data with $0.5^{\circ}$ resolution (i.e., roads in kilometers per $0.5^{\circ} \times 0.5^{\circ}$ grid).

Authors: Wenxiang Wu, Lingyun Hou

Map Designers: Qingyuan Ma, Jing'ai Wang, Ying Wang

Language Editor: Wenxiang Wu, Lingyun Hou

W. Wu $(\bowtie) \cdot$ L. Hou

Key Laboratory of Land Surface Pattern and Simulation, Institute of Geographic Sciences and Natural Resources Research, Chinese Academy of Sciences, Beijing, 100101, China

e-mail: wuwx@igsnrr.ac.cn
In order to accurately assess the impact of climate change on the road system in the future, we used the collected data of total road length, population, area, and per capita GDP of countries over the years to project the global road lengths under different Shared Socioeconomic Pathways (SSPs) in 2030 and 2050 by using the land coefficient method and finally obtained the global road length data with $0.5^{\circ}$ resolution under different SSPs in 2030 and 2050.

The dataset is about the global road network distribution, which is represented by the road length index, that is, the total length of roads in an area. It covers 166 countries/regions, reflecting the detailed spatial distribution of current and future roads in the world and improving the resolution from the national scale of the current projected global road data to $0.5^{\circ}$.

\section{Data}

In this study, the global road spatial distribution vector data were used to spatialize the current global roads; the historical road mileage, population, per capita GDP, and land area of various countries were used to fit the national land coefficient model, and the future global road spatial distribution was simulated and calculated by combining the population and economic data predicted by SSPs.

\subsection{Global Road Distribution Data}

We compared the global road dataset published by the Center for International Earth Science Information Network of Columbia University (https://sedac.ciesin.columbia.edu), DIVA-GIS road data system hosted by Robert J. Hijmans (http://dwww.diva-gis.org), and OpenStreetMap (https:// www.openstreetmap.org). For regions of China, we also 
considered the data of road distribution provided by the Resource and Environment Sciences and Data Center of the Institute of Geographic Sciences and Natural Resources Research, Chinese Academy of Sciences (http://www.resdc. cn). Considering the accuracy, comprehensiveness, and coverage of road data, and combined with online electronic maps such as Google Earth maps, the current global road distribution data were integrated as the basic data of global road data spatialization.

\subsection{Historical Data of Population, per Capita GDP, and Regional Area and Road Length}

The historical data of China's population, per capita GDP, and regional area and road length used in this study are from the provincial data of China Statistical Yearbook published by the National Bureau of statistics. Some of the statistical data are at the prefecture level, published in the provincial statistical yearbooks, and the time span is 1986-2016. The data of population, per capita GDP, and land area of other countries are from the world development indicators released by the World Bank (https://databank.worldbank. org/home.aspx). The total road length data are mainly from the World Bank (https://data.worldbank.org.cn) and the International Road Federation (https://www.irf.global) and supplemented by ASEAN statistical yearbook (https://www. aseansec.org). The time span is 1989-2014.

\subsection{Shared Socioeconomic Pathways Data}

This study projected the global road distribution in grids under SSP1, SSP2, and SSP3 scenarios in 2030 and 2050. The population and GDP forecast data used are derived from the global population and GDP data with $0.5^{\circ}$ resolution under the SSP1-SSP5 scenarios produced by Jiang et al. (2017). The original $0.5^{\circ}$ resolution population forecast data are from the global and national population data released by the International Institute for Applied Systems Analysis (IIASA), and the economic forecast data are from the GDP data provided by the Potsdam Institute for Climate Impact Research(PIK).

\section{Method}

For the production of the current global road length data, the current global road spatial distribution pattern was taken as the basis, and the global road length data with administrative regions as the basic statistical unit were disaggregated into the grids so as to realize the spatialization of global roads and obtain the global road spatial distribution data of $0.5^{\circ}$ grid.

This study mainly estimated the future global road network distribution based on the land coefficient method, which considers that road length is directly proportional to the square root of population and area and the economic index coefficient of the area where the road network is located. The method can be used to calculate the reasonable theoretical road length in an area (Guo 2005). The calculation formula is as follows:

$$
L=K \cdot \sqrt{P \cdot A}
$$

where $K$ is road network coefficient/economic coefficient; $P$ is population (unit: 10,000 people); $A$ is area (unit: 100 $\mathrm{km}^{2}$ ); and $L$ is road length.

The economic coefficient, population, and area in the model directly reflect the three most important influencing factors of the road network scale, which has strong practicability, and the results can reflect the actual demand of the projected area. Among the three parameters, the economic coefficient $K$ is calculated as follows.

First, the data of road length $\left(\mathrm{L}_{\mathrm{n}}\right)$, population $\left(\mathrm{P}_{\mathrm{n}}\right)$, and area $\left(A_{n}\right)$ over the years were used to calculate the economic coefficient $\mathrm{K}_{\mathrm{n}}$ :

$$
K_{n}=L_{n} / \sqrt{P_{n} \cdot A_{n}}
$$

The relationship between per capita GDP $\left(\mathrm{G}_{\mathrm{n}}\right)$ and the calculated $\mathrm{K}_{\mathrm{n}}$ is obtained through regression:

$$
K_{n}=a+b \cdot G_{n}
$$

where $a$ and $b$ are regression coefficients.

Using the land coefficient method and the historical data of road length, population, per capita GDP (economic coefficient $K$ ), and (regional) land area, we simulated the relationship between road length and socioeconomic factors. Combined with different SSPs scenarios in the future, the global road length data in 2030 and 2050 were obtained (Fig. 1).

\section{Results}

A comparison of the current and future road lengths of the 10 countries with the longest total road mileage in the world in 2010 indicates that the change of road length in the developed countries represented by the United States is very small and that in the developing countries such as India and China is relatively large (Fig. 2). 
Fig. 1 Technical flowchart of mapping future road network
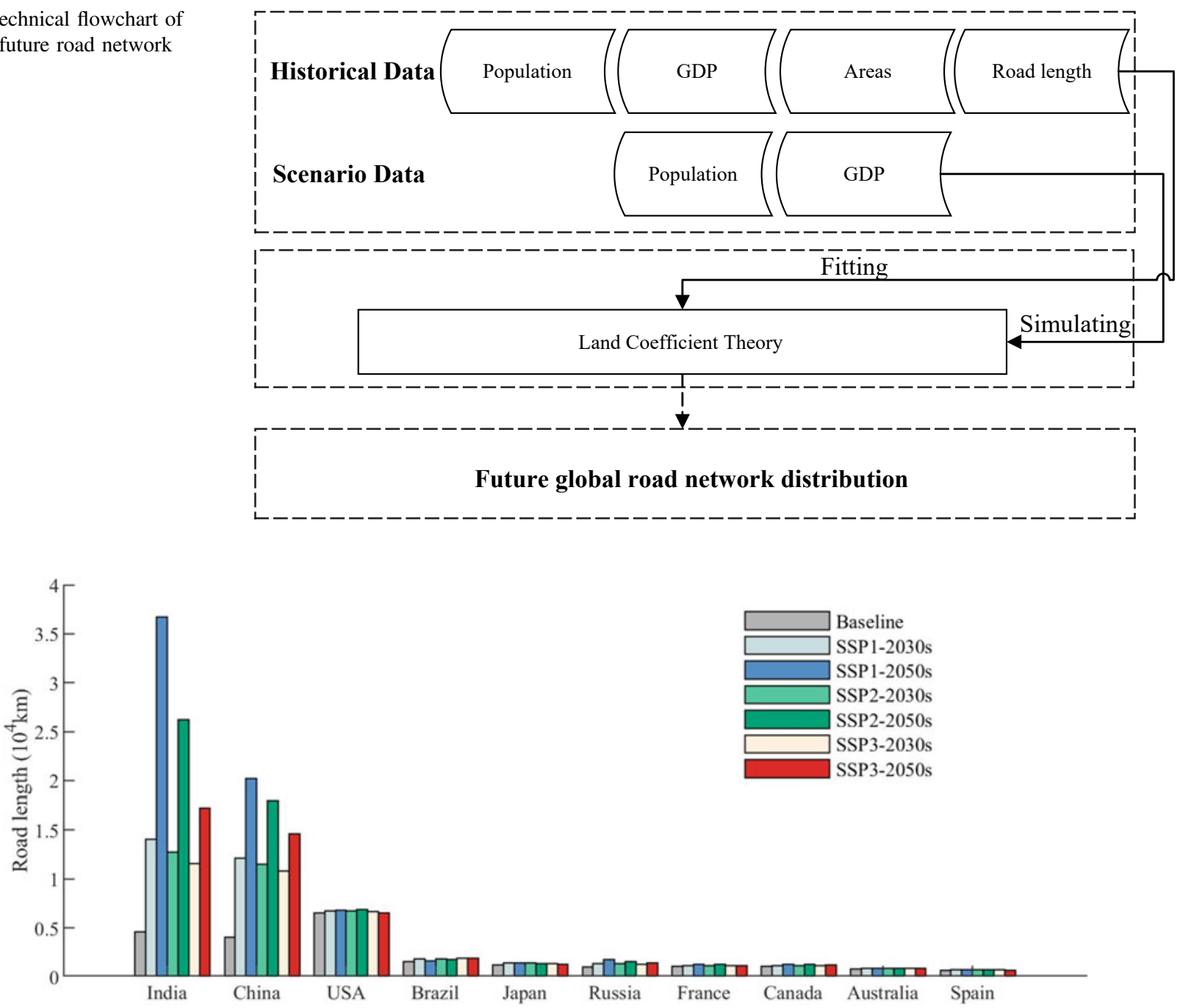

Fig. 2 Growth of road length of the top 10 countries with the longest total road mileage in 2010 under different Shared Socioeconomic Pathway (SSP) scenarios by 2030 and 2050

A comparison between Western Europe, northeastern United States, and the Bohai Rim of China indicates that the growth rate of road length in the Bohai Rim area is the highest, with clear differences under different SSPs and by different future years; while the growth rate of road length in Western Europe and the northeastern United States is not obvious, especially in the northeastern United States, which is similar to the current (2010) road length. The growth rate and trend of China's roads are similar to that of Asia as a whole, showing a high growth rate, and the growth rate varies significantly under different SSPs and by different years.
The total length of roads in all countries will increase significantly by 2030 and 2050. By 2030, the global total length of road will be about three times of the current (2010) total length, and by 2050, it will be about four to five times of the current level; the growth rate of the United States and Western Europe is the lowest, while that in Asia is the highest, especially in India and China. Under the sustainable development pathway SSP1 scenario, the growth of road network scale is the highest; under the regional competition pathway SSP3 scenario with higher challenges of climate change, the growth of road network scale is the smallest (Table 1).
Table 1 Growth scale of global roads under the Shared Socioeconomic Pathway (SSP) 1, SSP2, and SSP3 scenarios by 2030 and 2050

\begin{tabular}{l|l|l|l}
\hline & SSP1 & SSP2 & SSP3 \\
\hline 2030 & 3.02 & 2.88 & 2.71 \\
\hline 2050 & 5.48 & 4.52 & 3.77
\end{tabular}




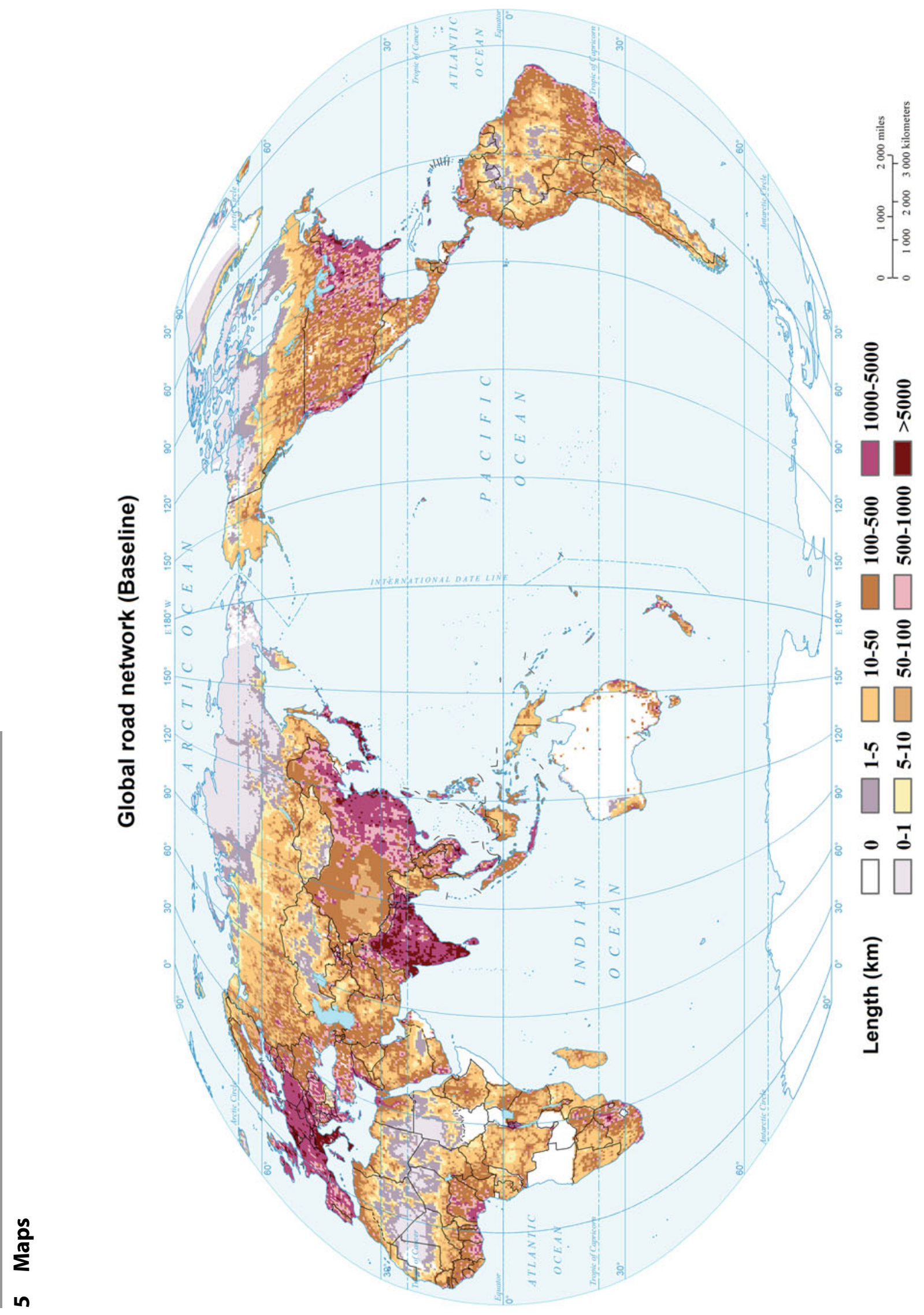


Projected global road network (2030, SSP1)

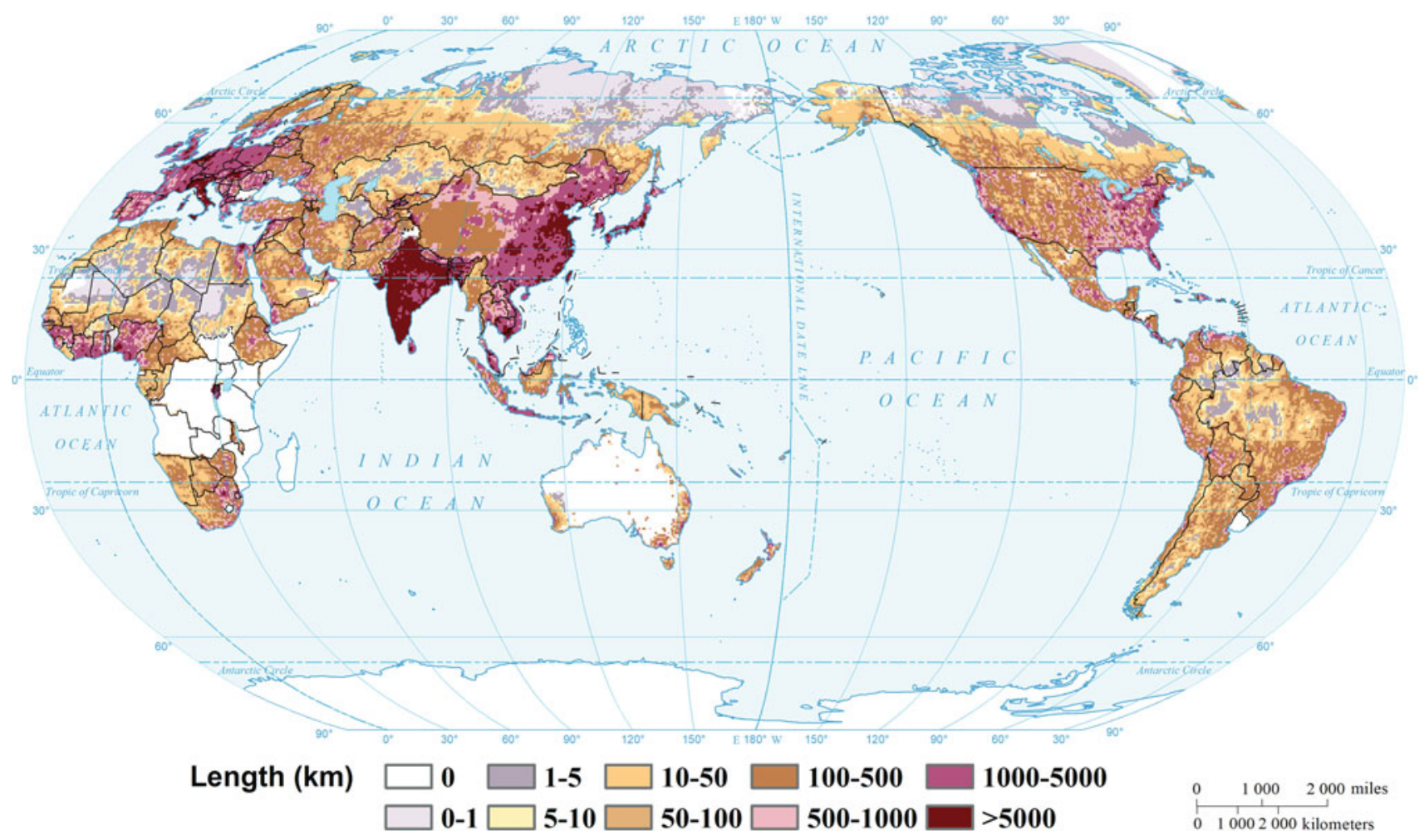

Projected global road network (2030, SSP2)

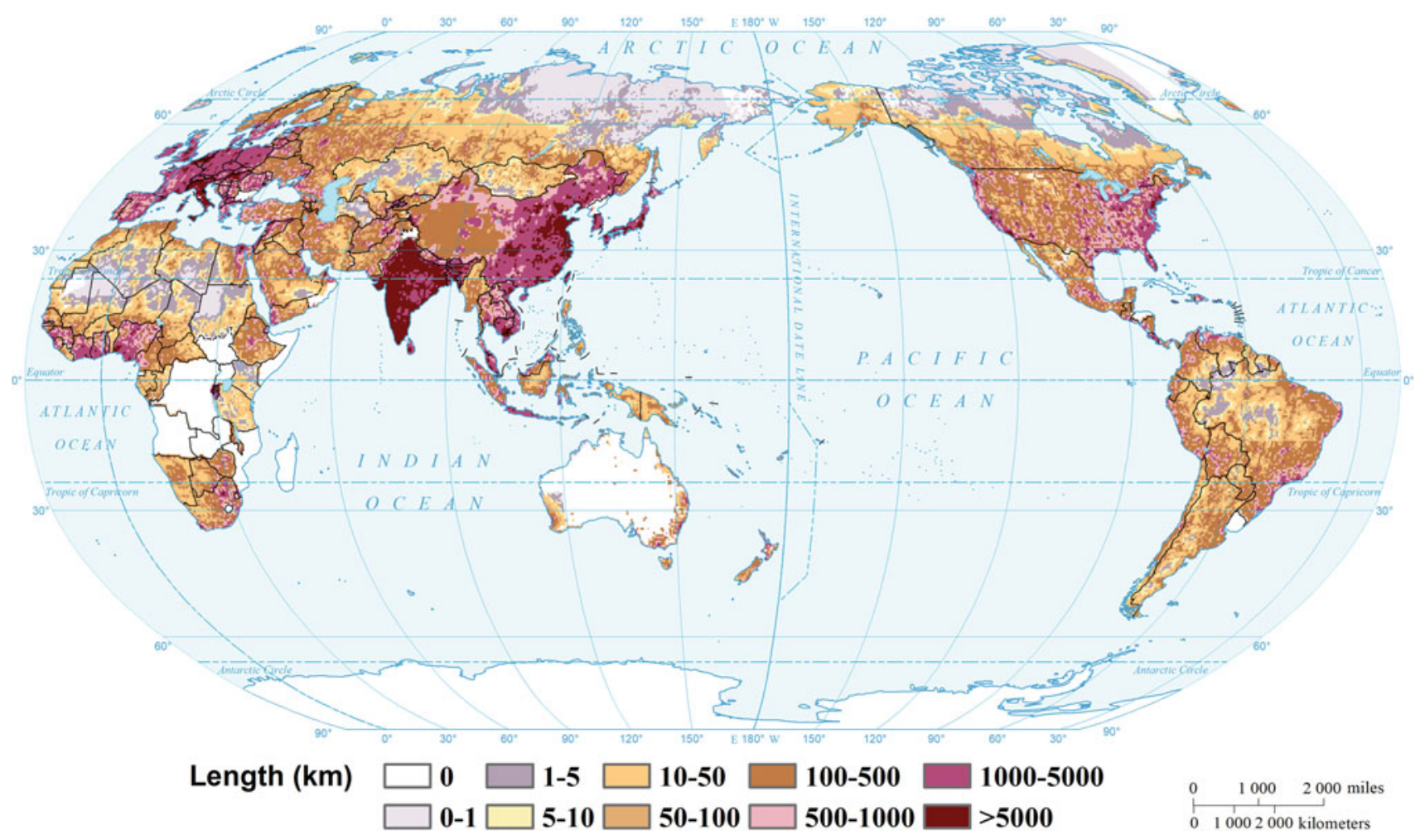




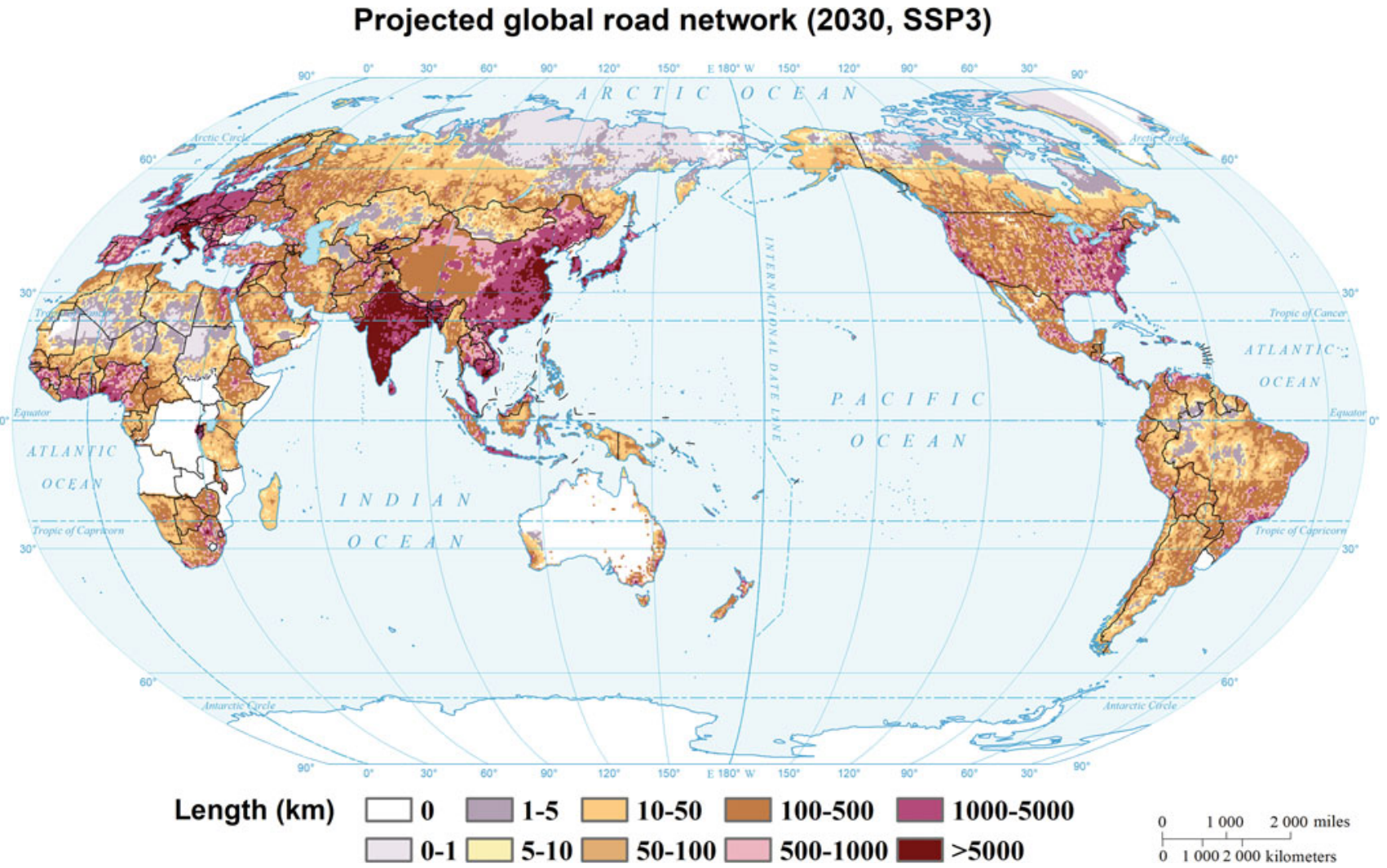

Projected global road network (2050, SSP1)

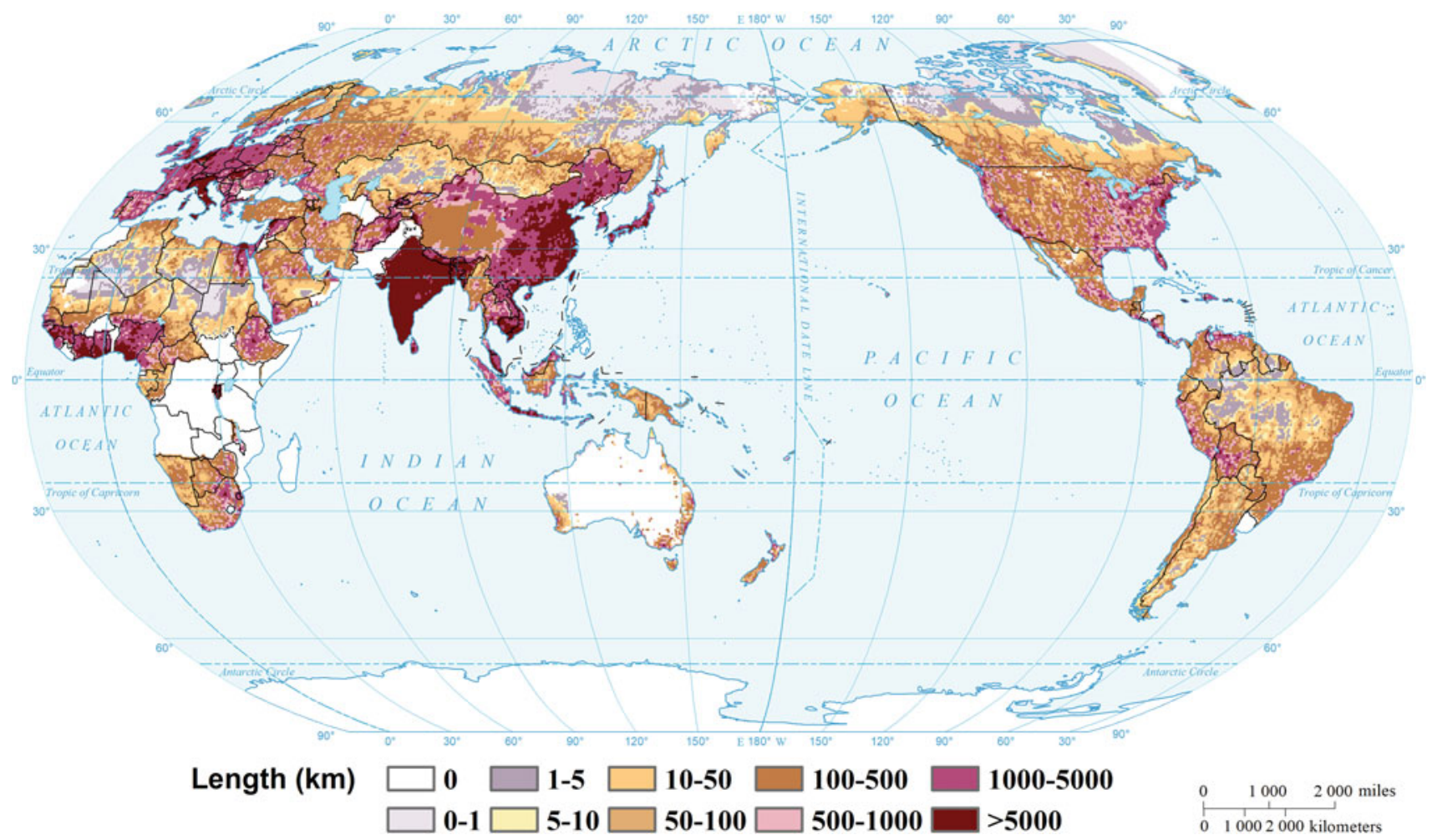


Projected global road network (2050, SSP2)

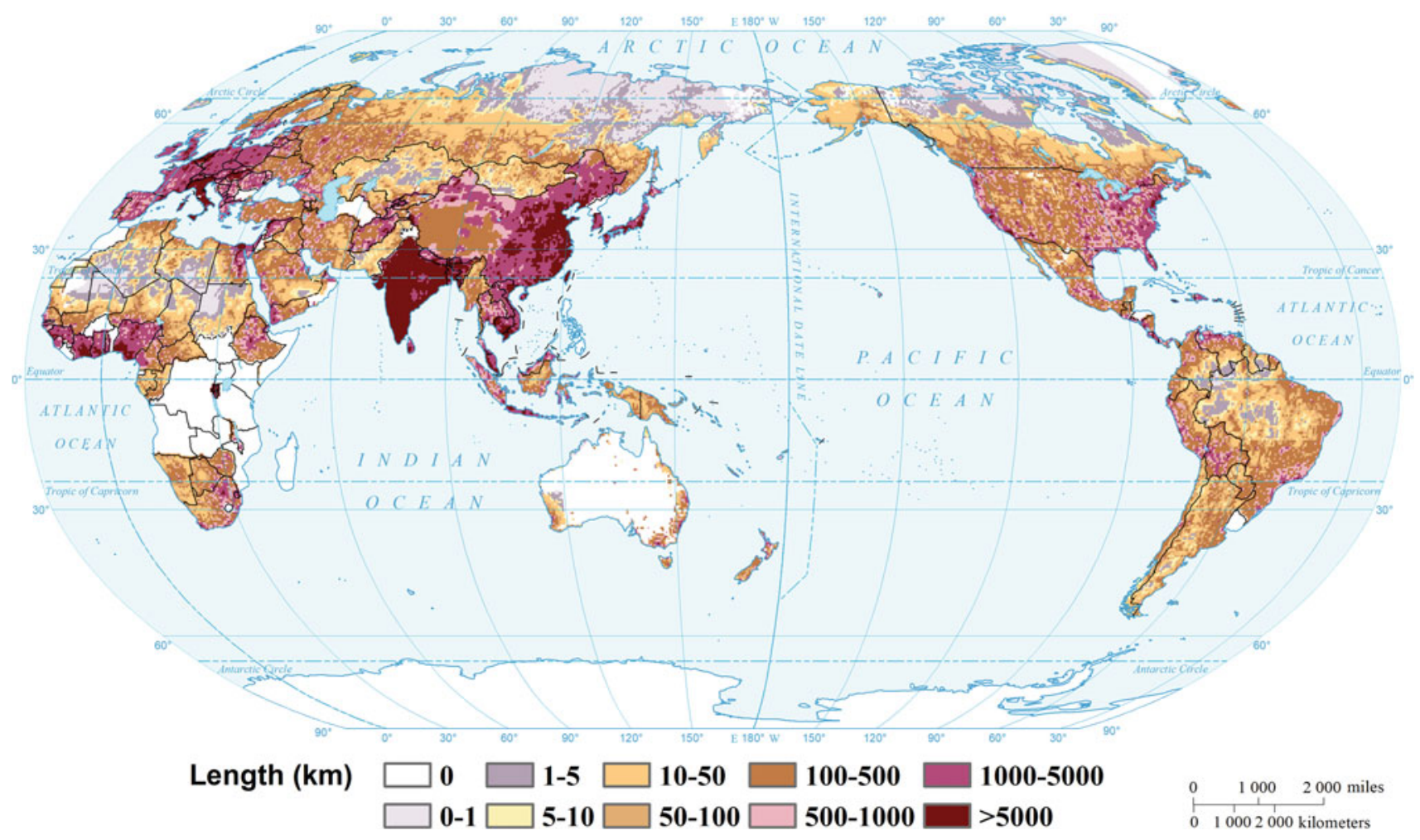

Projected global road network (2050, SSP3)

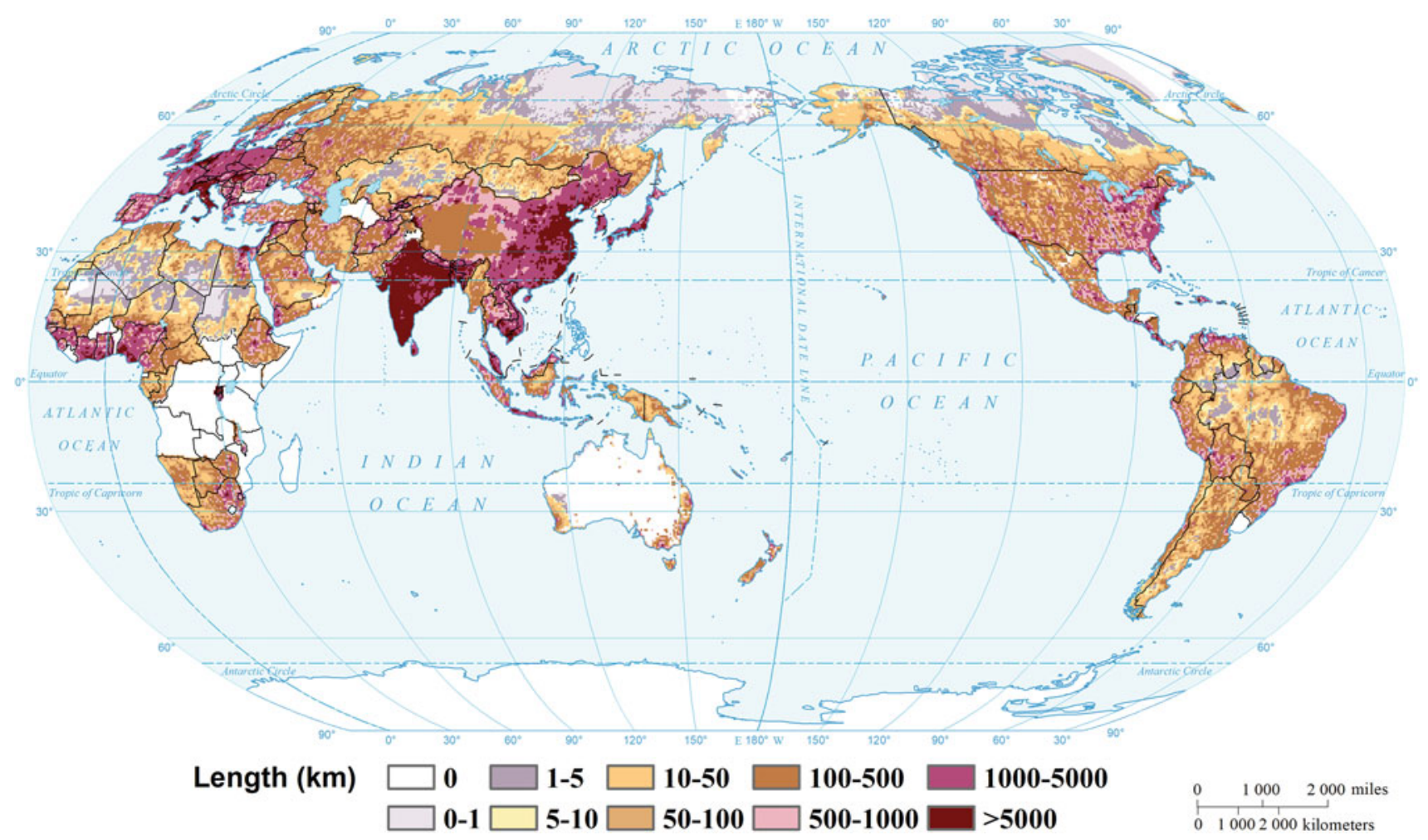




\section{References}

Guo, X.F. 2005. Application of land coefficient method in total mileage prediction of highway network. Highway 2: 77-80 (in Chinese).
Jiang, T., Zhao, J., Jing, C., Cao, L.G., Wang, Y.J., Sun, H.M., Wang, A.Q., Huang, J.L., Su, B.D., Wang, R. 2017. National and provincial population projected to 2100 under the shared socioeconomic pathways in China. Climate Change Research 13 (2): 128 137 (in Chinese).
Open Access This chapter is licensed under the terms of the Creative Commons Attribution 4.0 International License (http:// creativecommons.org/licenses/by/4.0/), which permits use, sharing, adaptation, distribution and reproduction in any medium or format, as long as you give appropriate credit to the original author(s) and the source, provide a link to the Creative Commons license and indicate if changes were made.
The images or other third party material in this chapter are included in the chapter's Creative Commons license, unless indicated otherwise in a credit line to the material. If material is not included in the chapter's Creative Commons license and your intended use is not permitted by statutory regulation or exceeds the permitted use, you will need to obtain permission directly from the copyright holder. 